\title{
PERBANDINGAN MAINTAINABILITY, FLEKSIBILITY, TESTABILITY PADA CMS OPEN SOURCE E-COMMERCE
}

\author{
Rini Anggrainingsih ${ }^{1 *}$, Aren Dwipa Pangastuti Suryono ${ }^{1}$, Umu Amanah Nur Rohmawati ${ }^{1}$ \\ ${ }^{1}$ Program Studi Informatika, Fakultas Matematika dan Ilmu Pengetahuan Alam, Universitas Sebelas Maret \\ Jl. Ir. Sutami 36A Kentingan Surakarta 57126 \\ *Email : rini.anggrainingsih@staff.uns.ac.id
}

\begin{abstract}
Content Management System (CMS) open source banyak digunakan dalam website e-commerce. CMS open source e-commerce tumbuh semakin canggih dan lebih kompetitif. Artikel ini berisi perbandingan kualitas software dari top three CMS open sourece e-commerce yaitu Magento, Woocomerce,dan OpenCart. perbandingan dilakukan terhadap kualitas revision software yaitu maintainability, fleksibility, dan testability. Kualitas revison diuji sebab maintenance dan testing merupakan proses yang sangat penting dalam pembuatan sebuah software dan memerlukan banyak resource. Pengukuran dilakukan dengan menggunakan phpmetric untuk menghitung maintainability index, afferent coupling, efferent couping, lack of cohesion method, cyclomatic complexity. Tujuan dari penulisan artikel ini adalah untuk menentukkan open source e-commerce terbaik dalam proses maintenance, adaptasi, dan modifikasi. Hasil menunjukkan bahwa magento memiliki kemampuan terbaik untuk maintenance, testing, dan perubahan kode dibandingkan Woocommerce dan Opencart, dimana nilai maintainaility indenxnya 111,36, afferent coupling 0,826, efferent coupling 1,83, Lack of cohesion method 2,10 dan Cyclomatic Complexity 11,02.
\end{abstract}

Keywords- Content Management System, E-Commerce, Kualitas Revision software, Maintenance, Opensorce.

\section{PENDAHULUAN}

Electronic commerce atau disingkat e-commerce merupakan aktifitas buying (pembelian), selling (penjualan) dan exchanging of product (penukaran produk) baik berupa service maupun informasi melalui suatu jaringan komputer yaitu internet [1]. Content management system (CMS) adalah suatu perangkat lunak yang digunakan untuk mengelola content suatu website [2]. Ada ratusan CMS e-commerce yang saat ini beredar dipasaran dan diantaranya merupakan software opensource [3].

Pertumbuhaan teknologi opensource tergolong tinggi, di ASEAN untuk sektor jasa keuangan saja pengadopsian open source telah bertumbuh sebesar 7,5 persen pada tahun 2016. Hal ini diprediksi akan terus berkembang menjadi lebih kompetitif, lebih cangih dan menghadirkan pelayanan yang lebih baik [4]. Sedangkan survey yang dilakukan oleh [5] menemukan bahwa 78 persen perusahaan telah menggunakan software open source, namun sebagian besar perusahaan tersebut kurang memperhatikan pengelolaan software yang digunakannya. Opensource banyak dipilih karena free dan menyediakan option yang dapat disesuaikan menurut kebutuhan pengguna. Berdasarkan hal tersebut software yang dipilih untuk diuji adalah software open source.

Survey yang dilakukan [6] menunjukkan bahwa Magento, OpenChart, dan Woocomerce merupakan Top tree CMS e-commerce opensource yang paling banyak digunkan oleh website e-commerce dengan presentase sebagai berikut: Woocomerce (34.8\%), Magento $(33.4 \%)$, dan Opencart $(6.3 \%)$. Berdasarkan hal tersebut CMS e-commerce opensource yang dipilih adalah Magento,OpenChart, dan Woocommerce.

Dalam industri software saat ini masalah maintenace software menjadi topik yang sering dibahas, sebab maintainance dan testing software merupakan proses penting yang menentukan kualitas dari suatu software. Maintenance dan testing memerlukan banyak sumber daya, setidaknya menghabiskan sepertiga sumber daya yang diperlukan dalam pembuatan suatu software. Membuat software yang mudah dalam maintenance, perubahan code, dan testing akan menghemat banyak pengeluaran. Software yang mudah dimaintenance, mudah dimodifikasi, dan mudah ditesting adalah software yang memiliki kualitas revison yang baik. Faktor kualitas revision diantaranya mintainability, fleksibility, dan testability. Maintainability software dapat diukur menggunakan maintainability index [7]. Menurut McCall subfaktor dari fleksibility adalah modularity, generality, self-descripness, dan simplicity. Mengukur nilai fleksibilitas suatu software dapat dilakukan dengan mengukur subfaktor modularity dan simplicity. Modularity dapat diukur melalui cohesion dan coupling [8]. Mengukur testability dapat dilakukan dengan mengukur kompleksitas suatu software. Komplesitas software diukur dengan cyclomatic complexity [9]. 
Terdapat banyak automated testing tool yang dapat digunakan untuk mengukur kualitas revison dari suatu software. Faktor kualitas revison yang diukur yaitu maintainability, fleksibility, dan testability, yang ditentukan oleh parameter maintainability index, afferent coupling, efferent coupling, cyclomatic complexity, dan lack of cohesion method. Sedangkan dari ketiga software yang diuji yaitu Magento, opencart, dan woocommerce semanya ditulis dalam bahasa pemrograman PHP sehingga diperlukkan tool yang dapat menganalis source code yang menggunakan bahasa pemrograman PHP. Dari paparan tersebut, maka tool yang digunakan adalah phpmetric.

Perbandingan CMS e-commerce sebelumnya sudah pernah dilakukan berdasarkan beberapa aspek yaitu hosting, installation, performace, support/community, content management, add-on module dan feature yaitu untuk membandingan antara Jomla (VirtueMart), Drupal (Uberchart), dan Magento [10]. Hasil yang diperoleh adalah VirtueMart dan Uberchart cocok digunakan pada toko kecil dan menengah, sedangkan Magento baik digunakan untuk toko besar yang berisikan ribuan produk. Pengukuran maintainability dan fleksibility software menggunakan phpmetric telah dilakukan untuk membandingkan learning management system yaitu Moodle, ILIAS, dan Atutor [11]. Dari hasil pengukuran didapat hasil bahwa tingkat maintainability dan fleksibility Moodle lebih baik daripada ILIAS dan Atutor.

Penelitian ini bertujuan untuk membandingkan software quality asurance revision factor (maintainability, fleksibility, dan testability) dari tiga CMS e-commerce opensource yaitu Magento versi 1.9.3.2, Openchart versi 2.3.0.3rc, dan Woocommerce versi 3.1.0. Pengukuran software quality asurance revision factor menggunakan automated software testing yaitu phpmetric versi 1.0.0. Perbandingan software quality asurance revision factor bertujuan untuk memperkirakan potensi kesulitan dalam maintenance, modification, dan adaptation dari suatu sistem yang menggunakan CMS e-commerce opensource.

\section{DASAR TEORI}

\section{A. Maintainability Index}

Maintainability index merupakan software metric yang digunakan untuk mengukur tingkat maintainability suatu software (seberapa mudah memaintenance, mensuport dan merubah source code dari suatu software) [7]. Mantainability index diukur dengan menggunakan rumus sebagai berikut:

Rumus original [12]

$M I=171-5.2 \times \ln (H V)-0.23 *(C C)-16.2 \times \ln (L O C)$

(1)

Rumus turunan yang digunakan oleh Phpmetrics [13]

$M I=171-5.28 \log (\mathrm{HV})-0.238(C C)-16.28 \log ($ LOC $)+$
(2)

$50 \sin (\operatorname{sqrt}(2.4 * C L O C / L O C))$

$$
\begin{aligned}
& \text { Dengan: } \\
& \mathrm{MI}=\text { Maintainability Index } \\
& \mathrm{HV}=\text { Halstead Volume } \\
& \mathrm{CC}=\text { Cyclomatic Complexity } \\
& \mathrm{LOC}=\text { Line of code } \\
& \mathrm{CLOC}=\text { Comment Lines of Code }
\end{aligned}
$$

Semakin tinggi nilai maintainability suatu code maka akan semakin mudah suatu software untuk dimaintenance. Phpmetric menggunakan score dari agka 0 - 118 untuk nilai maintainability index. Status maintainability software menurut phpmetric dibagi menjadi tiga [14] yaitu:

- $<64$ : Status maintainability rendah, project memiliki kesalahan teknis yang critical atau fatal.

- 65-84 : Status maintainability sedang, terdapat problem/masalah pada project namun tidak terlalu serius.

- > 85: Status maintainability tinggi, project termasuk dalam kondisi baik.

\section{B. Fleksibility}

Fleksibility pada software merupakan properti dari software yang mendefinisikan seberapa mudah suatu software diubah tanpa mengalami kerusakan [15]. Mengkur fleksibility suatu software dapat dilakukan dengan mengukur modularity dan simplicity. Modularity ditentukan oleh cohesion dan coupling. Cohesion menunjukkan keterkaitan antara fungsi-fungsi yang ada pada suatu modul, sedangkan coupling menunjukkan ketergantungan suatu modul terhadap modul lainnya. Software dikatakan memiliki modularity yang baik apabila memiliki cohesion yang tinggi dan coupling yang rendah [8]. Phpmetric mengukur cohesion dengan LCOM (Line of Cohesion Method) sedang untuk mengukur coupling diukur dengan Afferent Coupling dan Efferent Coupling. Afferent coupling menunjukkan jumlah relasi antar kelas dalam satu package, sedangkan efferent coupling menunjukkan jumlah relasi antar kelas dalam package yang berbeda. Semakin tinggi jumlah relasinya maka kompleksitas akan naik dan source code menjadi sulit dimodifikasi [16]. simplicity menunjukkan kompleksitas suatu software, dalam phpmetric kompleksitas diukur dengan cyclomatic complexity. Nilai cyclomatic complexity suatu software yang besar menandakan tingginya jumlah alur kontrol dalam suatu modul sehingga kompleksitas software tersebut menjadi besar.

\section{Testability}

Testability merupakan salah satu faktor penentu kualitas suatu software. Definisi testability secara umum adalah seberapa mudah untuk melakukan testing pada suatu software. Semakin rendahnya nilai testability suatu software menunjukkan semakin sulit dalam melakukan 
testing dan maintenance suatu software. Testability menjadi faktor penting yang menentukkan banyaknya waktu dan effort yang diperlukan untuk melakukan testing software [17]. Faktor-faktor yang mempengaruhi testability diantarannya modifiability, simplicity, understandability, fleksibility, complexity, selfdescriptiveness dan modularity [18]. Developer software biasanya mengaitkan pengukuran complexity dengan banyaknya resource yang harus dialokasikan untuk testing. Semakin tinggi nilai complexity maka semakin sulit suatu software untuk dimengerti, semakin sulit menemukan error, dan tentu saja mempersulit dalam proses testing [9].

\section{Phpmetrics}

Phpmetric merupakan automated testing tool yang dapat dipergunakan untuk menghitung kualitas software yang dibuat dengan bahasa pemrograman PHP serta menampilkan hasil perhitungan tersebut dalam tabel, grafik, maupun ilustrasi [19]. Phpmetric memiliki banyak sekali jenis pengukuran software, beberapa diantaranya adalah sebagai berikut [16]:

- Maintainability Index : mengukur tingkat maintainability suatu software

- Lack of Cohesion Method : menghitung jumlah dari method -method berbeda dalam suatu kelas yang menggunakan variabel dalam kelas tersebut

- Cyclomatic Complexity : menghitung kompleksitas suatu program dengan mengukur banyaknya alur kontrol dalam suatu modul

\section{METODOLOGI}

Pengukuran maintainability, fleksibility, dan testability pada opensource CMS e-commerce melalui tahapantahapan sebagai berikut:

1) Mendownload source code CMS e-commerce opensource diantanya Magento versi 1.9.3.2, Openchart versi 2.3.0.3rc, dan Woocommerce versi 3.1.0. Source code didownload melalui github.

2) Source code dari setiap CMS e-commerce opensource yang didownload dianalisis menggunakan phpmetrics. Hasil analisis dengan phpmetric berupa report file html, dan untuk mengenerate report tersebut dilakukan dengan cara:

- Menginstal composer

- Mendownload phpmetric.phar dan menyimpannya pada lokasi tertentu.

- Menggetikkan perintah pada command prompt sebagai berikut

php phpmetric.phar --report-html=file_report_name.html location/of/your/sourcecode

- Report akan digenerate dan disimpan secara otomatis dilokasi tempat phpmetrics.phar disimpan.
Dikarenakan batasan memory dari PHP, maka untuk menganalis source code dari setiap CMS e-commerce opensource harus dibagi kedalam beberapa folder dan dianalisis secara terpisah masing-masing folder.

3) Hasil report yang didapat pada tahap 2 dipindahkan kedalam Ms.excel kemudian mencari ratarata nilai Maintainability Index, Afferent Coupling, Effrent Coupling, Line of Cohesion Method, Cyclomatic Complexity dari setiap file berkestensi .php yang ada pada CMS e-commerce opensource.

\section{PEMBAHASAN}

\section{A. Source code CMS}

Dalam melakukan pengujian, terdapat tiga buah open source e-commerce yang diuji diantaranya Magento, Opencart, dan Woocommerce. Adapun rincian dari opencource yang diunduh dapat dilihat pada Tabel I

TABEL I

RINCIAN SOURCE CODE CMS YANG DIUJI

\begin{tabular}{|l|l|c|c|}
\hline \multicolumn{1}{|c|}{ CMS } & \multicolumn{1}{|c|}{ Laman Download } & Versi & $\begin{array}{c}\text { Ukuran } \\
\text { file }\end{array}$ \\
\hline Magento & $\underline{\text { https://github.com/mage }}$ & 1.9 .3 .2 & $35,3 \mathrm{MB}$ \\
nto, & $\underline{\text { https:/github.com/open }}$ & 2.3 .0 .3 & $12,3 \mathrm{MB}$ \\
\hline Opencart & $\underline{\underline{\text { cart/opencart, }}}$ & 3.1 .0 & $2,36 \mathrm{MB}$ \\
\hline $\begin{array}{l}\text { Woocom } \\
\text { merce }\end{array}$ & $\begin{array}{l}\text { https:/github.com/wooc } \\
\text { ommerce/woocommerce }\end{array}$ & & \\
\hline
\end{tabular}

\section{B. Menjalankan PhpMetrics}

Dalam melakukan analisa faktor maintainability, testability, dan fleksibility dari ketiga open source ecommerce (Magento, Opencart, dan Woocommerce), digunakan sebuah automated software quality tool PhpMetrics. PhpMetrics merupakan tool yang akan mengecek semua file bertipe php.

Adapun contoh salah satu rincian hasil pengujian software menggunakan phpmetrics dapat dilihat pada Gbr. 1. Dimana Gbr. 1 merupakan rincian pengujian pada folder catalog open source opencart. 


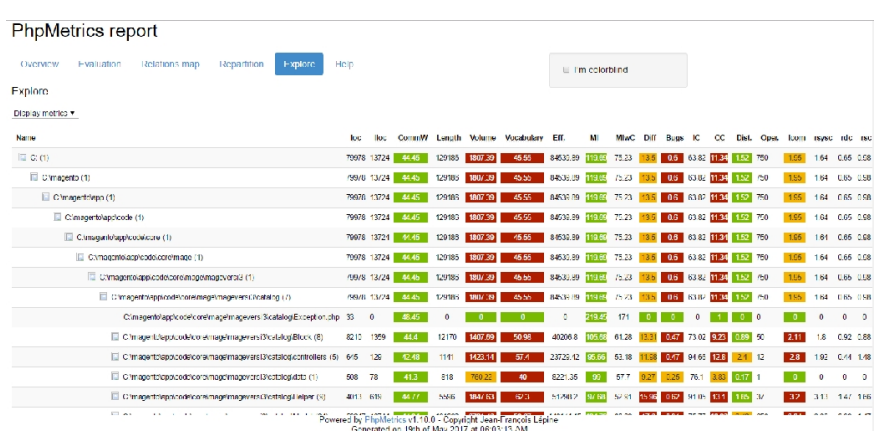

Gbr. 1 Rincian Pengujian yang dilakukan pada Folder Catalog Opencart

C. Analisa Hasil Pengujian

\section{1) Maintainability Index}

Hasil pengukuran maintainability index untuk setiap software opensource CMS e-commerce yang diukur dengan phpMetrics ditunjukkan pada Tabel II, Tabel III, dan Tabel IV. Dimana pada Tabel II ditunjukkan hasil pengukuran maintainability index pada software Magento. Pada Tabel III ditunjukkan hasil pengukuran maintainability index pada software Opencart. Pada Tabel IV ditunjukkan hasil pengukuran maintainability index pada software Woocommerce.

Dalam pengukuran maintanaibility, pada setiap folder yang diuji memiliki index maintainability yang menunjukkan mudah tidaknya suatu open source untuk dimaintain. Nilai ini didapat dari perhitungan rumus turunan yang digunakan oleh Phpmetrics seperti pada rumus(2).

Tabel II menunjukkan hasil pengukuran Maintainability di setiap folder utama pada software Magento versi 1.9.3.2 Dimana analisis dilakukan pada folder app, downloader, error, include, js, lib, shell, dan file yang berada di luar folder-folder utama yang diberi nama folder "root".

TABEL II

HASIL PENGUKURAN MAINTAINABILITY PADA SOFTWARE MAGENTO 1.9.3.2

\begin{tabular}{|c|c|}
\hline Folder & Index Maintainability (MI) \\
\hline Root & 86.274 \\
\hline App & 119.159 \\
\hline downloader & 118.935 \\
\hline errors & 107.517 \\
\hline includes & 220.73 \\
\hline Js & 85.42 \\
\hline Lib & 96.642 \\
\hline shell & 453.5 \\
\hline
\end{tabular}

Tabel III menunjukkan hasil pengukuran maintainability di setiap folder utama pada software Opencart versi 2.3.0.3. Dimana analisis dilakukan pada folder Admin, Catalog, install, system, dan file yang berada di luar folder-folder utama yang diberi nama folder "root".
TABEL III

HASIL PENGUKURAN MAINTAINABILITY PADA SOFTWARE OPENCART 2.3.0.3

\begin{tabular}{|c|c|}
\hline Folder & Index Maintainability (MI) \\
\hline Root & 137,445 \\
\hline Admin & 55,90827303 \\
\hline Catalog & 64,26747368 \\
\hline Install & 70,47425 \\
\hline System & 52,73981818 \\
\hline Rata-Rata & 59.76 \\
\hline
\end{tabular}

Tabel IV menunjukkan hasil pengukuran maintainability di setiap folder utama pada software Woocommerce versi 3.10. Dimana analisis dilakukan pada folder i18n, include, template, dan file yang berada di luar folder-folder utama yang diberi nama folder "root".

TABEL IV

HASIL PENGUKURAN MAINTAINABILITY PADA SOFTWARE WOOCOMMERCE 3.10

\begin{tabular}{|c|c|}
\hline Folder & Index Maintainability (MI) \\
\hline Root & 58,17 \\
\hline i18n & 108,888 \\
\hline Include & 76,994 \\
\hline Template & 111,605 \\
\hline Rata-Rata & 87,625 \\
\hline
\end{tabular}

Berdasarkan hasil pengukuran ketiga software yaitu Magento, opencart dan Woocommerce didapatkan nilai rata-rata pada setiap software yang ditunjukkan pada Tabel V. Dimana Tabel V menunjukkan hasil pengukuran rata-rata maintainability index untuk setiap CMS adalah sebagai berikut:

- Magento

Hasil pengukuran rata-rata nilai maintainability index adalah 111,36 yang artinya Magento memiliki nilai maintainability yang tinggi (Sulit dimaintenance).

- Openchart Hasil pengukuran rata-rata nilai maintainability index adalah 59,76 yang artinya Open chart memiliki nilai maintainability yang tendah (mudah dimaintennace).

- Woocomerce

Hsil pengukuran rata-rata nilai maintainability index adalah 87,63 yang artinya Woocommerce memiliki nilai maintainability yang tergolong tinggi.

TABEL V

HASIL RATA-RATA DARI PENGUJIAN MAINTAINABILITY

\begin{tabular}{|c|c|}
\hline Software (CMS e-commerce) & Maintainability Index (MI) \\
\hline Magento & 111,36 \\
\hline Opencart & 59,76 \\
\hline Woocommerce & 87,63 \\
\hline
\end{tabular}


TABEL VII

HASIL PENGUKURAN SIMPLICITY

\section{Pengukuran Modularity}

Hasil pengukuran Modularity didapat dari hasil subfaktornya. Dimana subfaktor Modularity adalah Cohesion dan Coupling. Software dikatakan memiliki modularity yang baik apabila memiliki nilai cohesion yang tinggi dan nilai coupling yang rendah. Tabel VI menampilkan nilai cohesion dan coupling pada software Magento, Opencart, dan Woocommerce yang telah diuji.

Hasil pengukuran tersebut menunjukkan bahwa Magento memiliki nilai Afferent couping $=0,826$, Efferent Coupling $=1,83$, dan cohesion $=2,10$. Opencart memiliki nilai Afferent couping $=0,07$, Efferent Coupling $=0,24$, dan cohesion $=0,71$. Sedangkan Woocommerce memiliki nilai Afferent couping $=0,741$, Efferent Coupling $=1,321$, dan cohesion $=3,669$.

Software dikatakan memiliki modularity yang baik apabila memiliki cohesion yang tinggi dan coupling yang rendah [8]. Dari hasil pengukuran cohesion dan coupling, didapat wooocommerce dam magento memiliki nilai cohesion yang tinggi dan coupling yang rendah. Hal ini berbeda dengan software opencart yang memiliki coupling dan coheren yang rendah. Sehingga wooocommerce dam magento memiliki modularity yang baik.

TABEL VI

HASIL PENGUKURAN MODULARITY

\begin{tabular}{|c|c|c|c|}
\hline $\begin{array}{c}\text { Software } \\
\text { (CMS e- } \\
\text { commerce) }\end{array}$ & $\begin{array}{c}\text { Afferent } \\
\text { Coupling } \\
\text { (AC) }\end{array}$ & $\begin{array}{c}\text { Efferent } \\
\text { Coupling } \\
\text { (EC) }\end{array}$ & $\begin{array}{c}\text { Lack Of } \\
\text { Cohesion of } \\
\text { Method (LCOM) }\end{array}$ \\
\hline Magento & 0,826 & 1,83 & 2,10 \\
\hline Opencart & 0,07 & 0,24 & 0,71 \\
\hline Woocommerce & 0,741 & 1,321 & 3,669 \\
\hline
\end{tabular}

\section{E. Pengukuran Simplicity}

Semakin tinggi nilai Cyclomatic Complexity (CC) semakin semakin kompleks suatu software (simplicity tinggi) [9]. Tabel VII menampilkan hasil pengukuran simplicity dari software Magento, Opencart, dan Woocommerce. Dimana software Magento memiliki kompleksitas $=11,02$ yang termasuk dalam kategori rendah, software Opencart memiliki kompleksitas = 18,82 yang termasuk dalam kategori sedang, dan Woocommerce memiliki kompleksitas $=29$ yang termasuk dalam kategori tinggi. Sehingga diketahui bahwa magento memiliki nilai complexity yang paling rendah dibanding Opencart dan Woocommerce.

\begin{tabular}{|c|c|}
\hline Software (CMS e-commerce) & Cyclomatic Complexity \\
\hline Magento & 11,02 \\
\hline Opencart & 18,82 \\
\hline Woocommerce & 29 \\
\hline
\end{tabular}

\section{KESIMPULAN}

Berdasarkan dari hasil pengukuran dan perbandingan yang telah dilakukan, diketahui bahwa software Magento memiliki nilai Index Maintainability sebesar 111,36. Afferent Coupling (AC) sebesar 0,826, Efferent Coupling (EC) sebesar 1,83 Lack Of Cohesion of Method (LCOM) sebesar 2,10 dan Cyclomatic Complexity sebesar 11,02.

Software opencart memiliki nilai Index Maintainability sebesar 59,76. Afferent Coupling (AC) sebesar 0,07, Efferent Coupling (EC) sebesar 0,24, Lack Of Cohesion of Method (LCOM) sebesar 0,71 dan Cyclomatic Complexity sebesar 18,82.

Sedangkan software woocommerce memiliki nilai Index Maintainability sebesar 87,63. Afferent Coupling (AC) sebesar 0,741, Efferent Coupling (EC) sebesar 1,321, Lack Of Cohesion of Method (LCOM) sebesar 3,669 dan Cyclomatic Complexity sebesar 29.

Sehingga dari hasil tersebut dapat disimpulkan bahwa Magento mudah di maintain dengan nilai, mudah di tes (testability), dan mudah dimodifikasi (fleksibility) dibandingkan Opencart dan Woocommerce.

\section{REFERENSI}

M. Dhakate, "Study of Content Management System (CMS) for Developing E-Commerce Websites," Indian J. Appl. Res., vol. 5, no. 8, pp. 456-458, 2015.

[2] M. Fakhriza et al., "Aplikasi Content Management System ( Cms ) Pada Joomla Untuk Membuat Web Service," no. 9, pp. 11-13.

[3] M. Shaikh and V. Fegade, "Modeling Essentials of Content Management System (CMS) for Web-Based MIS Application," Int J. Eng. Technol., vol. 2, no. 3, pp. 132-136, 2012.

[4] Pressreader, "Inovasi Open Source di ASEAN," www.pressreader.com, 2017. [Online]. Available: https://www.pressreader.com/indonesia/info-

komputer/20170207/281513635897546. [Accessed: 16-Jun-2017].

[5] S. J. Vaughan-Nichols, "It's an open-source world: 78 percent of companies run open-source software," zdnet.com, 2015. [Online]. Available: http://www.zdnet.com/article/its-an-open-sourceworld-78-percent-of-companies-run-open-source-software/.

[Accessed: 15-Jun-2017].

[6] BuiltWith, "Open Source Usage-Statistics for websites using Open Source technologies," trends.builtwith.com, 2017. [Online]. Available: https://trends.builtwith.com/shop/open-source. [Accessed: 09-Jun-2017].

[7] N. M. A. M. Najm, "Measuring Maintainability Index of a Software Depending on Line of Code Only," vol. 16, no. 2, pp. 64-69, 2014.

[8] M. Ghasemi, S. M. Sharafi, and A. Arman, "Towards an Analytical Approach to Measure Modularity in Software Architecture Design," J. Softw., vol. 10, no. 4, p. 465, 2015.

[9] K. W. M. \& J. E. P. J.M. Voas, "A comparison of a dynamic software testability metric to static cyclomatic complexity," Trans. 
Inf. Commun. Technol., vol. 8, 1994.

[10] S. Arabia and S. Arabia, "COMPARING E-COMMERCE CONTENT MANAGEMENT," vol. 53, no. 3, 2013.

[11] R. Anggrainingsih, "Comparison of Maintainability and Flexibility on Open Source LMS," pp. 273-277, 2016.

[12] D. Coleman, D. Ash, B. Lowther, and P. Oman, "Using metrics to evaluate software system maintainability," Computer (Long. Beach. Calif)., vol. 27, no. 8, pp. 44-49, 1994.

[13] Steve Pavarno, "metric documentation: first experiment \#241," github.com, $2017 . \quad$ [Online]. Available: https://github.com/phpmetrics/PhpMetrics/pull/241/files. [Accessed: 13-Jun-2017].

[14] J.-F. Lépine, "How to understand the PhpMetrics' metrics," phpmetrics.org, 2015. [Online]. Available: $\mathrm{http}$ :/www.phpmetrics.org/documentation/how-to-understandmetrics.html. [Accessed: 09-Jun-2017].

[15] L. Shen and S. Ren, "Analysis and measurement of software flexibility based on flexible points," pp. 331-341, 1990.

[16] J.-F. Lépine, "Metrics of PhpMetrics," phpmetrics.org, 2015. [Online]. Available: http://www.phpmetrics.org/documentation/index.html. [Accessed: 13-Jun-2017]

[17] D. R. S. Abdullah, Dr. M.H. Khan, "F LEXIBILITY : A K EY F ACTOR T O," Int. J. Softw. Eng. Appl., vol. 6, no. 1, pp. 89-99, 2015.

[18] M. H. Khan and R. Srivastava, "T ESTABILITY M EASUREMENT M ODEL F OR O BJECT O RIENTED D ESIGN ( T MM OOD )," vol. 7, no. 1, pp. 153-163, 2015.

[19] P. Aba, "phpmetrics of popular php projects," peteraba.com, 2014. [Online]. Available: https://peteraba.com/blog/phpmetrics-ofpopular-projects/. [Accessed: 16-Jun-2017]. 